\title{
Preface from the Dean
}

It is my great honor to welcome you to the 6th Environmental Technology and Management Conference (ETMC) in conjunction with the 12th AUN/SEED-Net Regional Conference on Environmental Engineering (RC EnvE) 2019. Environmental engineering has been participating in attempts of achieving sustainable development goals (SDGs). Environmental issues are among the goals and targets for the SDGs, such as:

- ensuring healthy lives and promote well-being for people of all ages,

- ensuring availability and sustainable management of water and sanitation,

- ensuring the access to affordable, reliable, sustainable and modern energy,

- building resilient infrastructure,

- promoting inclusive and sustainable industrialization and fostering innovation,

- making cities and human settlements inclusive, safe, resilient and sustainable,

- taking urgent action to combat climate change and its impact,

- conserving and sustaining the oceans, seas and marine resources for sustainable development,

- protecting restore and promoting sustainable use of the terrestrial ecosystem,

- sustaining forests management, combating desertification, and

- reserving land degradation and halting the biodiversity loss.

As with sustainable development innovations, stakeholders and researchers need to collaborate while focusing on the goals. The Environmental Technology and Management Conference (ETMC) in conjunction with AUN/SEED-Net Regional Conference on Environmental Engineering (RC EnvE) 2019 with the theme "Towards Smart and Green Innovations for a Safe, Resilient, and Sustainable Environment" is expected to be an important momentum for sustainable development and awareness in protecting human health, safety, and environment.

This conference is the sixth conference after the last one was previously held in 2015. In this sixth conference, ITB had the opportunity to work with AUN/SEED-Net. I hope that the conference will be able to provide a platform for exchanging ideas, information, and experiences among academics, researchers, consultants, engineers, manufacturers, and postgraduate scholars. It is also can be a medium to discuss and evaluate the latest research, innovative technologies, policies and new directions in infrastructure development, pollution prevention and eco-friendly technologies adapted to developing countries, and to promote cooperation and networking amongst practitioners and researchers involved in addressing green infrastructure and environment issues.

Lastly, I would like to thank the sponsors for the support for this conference, the organizing committee, and all students who have been working very hard to organize this event. Enjoy your time in Bali and I hope we have a fruitful discussions and potential collaborations in the future. 
Bali, November 05, 2019

Prof. Ir. Ade Sjafruddin, M.Sc., Ph.D.

Dean, Faculty of Civil and Environmental Engineering

Institut Teknologi Bandung 